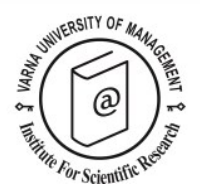

\title{
Enhancing Cultural Heritage Experiences with Smart Technologies: An Integrated Experiential Framework
}

\author{
Piera Buonincontri ${ }^{1 *}$ and Alessandra Marasco ${ }^{2}$
}

Received: 31/10/2016 Accepted: 07/02/2017

\footnotetext{
1 Institute for Research on innovation and Services for Development (IRISS), National Research Council (CNR), Via Cardinale G. Sanfelice 8, 80134, Napoli, Italy; phone: +39 081 2470940, e-mail: p.buonincontri@iriss.cnr.it

${ }^{2}$ Institute for Research on innovation and Services for Development (IRISS), National Research Council (CNR), Via Cardinale G. Sanfelice 8, 80134, Napoli, Italy

* Corresponding author
}

\begin{abstract}
The paper addresses how smart technologies can be used to enhance cultural heritage experiences at tourism destinations. As its main contribution, it presents a framework to leverage the potential of multiple smart technologies throughout the visitors' experience at cultural heritage sites. The proposed framework builds on the theoretical foundation of the experience economy and the results of an analysis of best practices of smart technologies applied to cultural heritage sites. The analysis examines the capability of these technologies to intensify the four experience dimensions identified by Pine and Gilmore (1998) - Entertainment, Esthetic, Education and Escapism - in relation to an extended perspective of the visitors' experience including the three stages of the visit. The pilot testing of the framework provides insights into the opportunities to use a combination of applications for facilitating and enriching the cultural visit at the destination according to a multi-stage and multidimensional perspective of the heritage experience. The integrated perspective proposed in the paper provides a contribution to advance theory and practice, based on the more comprehensive view of the potential role of smart technologies' in heritage experiences deriving from an integrated multi-stage and multi-dimensional analysis.
\end{abstract}

(C) 2017 Varna University of Management. All rights reserved

Keywords: Cultural heritage experience; smart technologies; tourism destination; experience stages; experience dimensions.

Citation: Buonincontri, P., A. Marasco (2017) Enhancing Cultural Heritage Experiences with Smart Technologies: An Integrated Experiential Framework. European Journal of Tourism Research 17, pp. 83-101

\section{Introduction}

The emergence of smart technologies has provided extraordinary possibilities to facilitate and enrich the experiences of visitors at heritage sites with relevant implications for the marketing and attractiveness of cultural tourism destinations (Chung, Han and Joun, 2015; Han, tom Dieck and Jung, 2017; Jung and tom 
Dieck, 2017; Jung, tom Dieck, Lee and Chung, 2016; Tscheu and Buhalis, 2016). Research in this area demonstrates the potential of different technologies to support and enhance visitors' experiences at heritage sites, including mobile Augmented Reality (Angelopoulou, Economou, Bouki, Psarrou, Jin, Pritchard, Kolyda, 2012; Cranmer, tom Dieck, and Jung, 2017; Han, Jung and Gibson, 2013; Kourouthanassis, Boletsis, Bardaki, Chasanidou, 2015; tom Dieck and Jung, 2016, 2017), Virtual Reality (Huang, Backman, Backman, and Moore, 2013; Guttentag, 2010; Jung, tom Dieck, Lee, and Chung, 2016; Pantano, 2011), wearable devices (Leue, Jung and tom Dieck, 2015; tom Dieck, Jung, and Han, 2016). However, most of the existing technological applications and related studies only focus on the on-site stage of the cultural heritage experience. Such a focus appears to be too narrow in relation to the perspective of technology-enhanced tourism experiences (Neuhofer et al., 2012, 2015), which emphasizes the important role of technologies in all the three main stages of the tourist experience, namely the pre-travel, the on-site and the post-travel stages. Indeed, recent research in the specific context of cultural heritage highlights the need to understand how smart technologies can enhance the cultural heritage experience by extending its boundaries to include pre- and post-visit stages (Kuflik, Wecker, Lanir and Stock, 2015; Jung and tom Dieck, 2017).

Furthermore, the application of smart technologies should take into account the multifaceted nature of the heritage experience. Cultural heritage attractions are 'experiential' products that can facilitate feelings of fun and enjoyment, escape from routine, sharing valued time with family or friends, or learning (Mclntosh, 1999). Accordingly, tourism studies analyse the experience of cultural heritage sites and attractions as a multi-dimensional construct in order to capture the range of visitors' thoughts, feelings, emotional reactions, sensations, activities, benefits (Buonincontri, Marasco, and Ramkissoon, 2017; Chen and Chen, 2010, 2013; Masberg and Silverman, 1996; Mclntosh and Prentice, 1999; Sheng and Chen, 2012). In this respect, studies have demonstrated the applicability of the four realms of experience identified by Pine and
Gilmore (1998) - Aesthetic, Entertainment, Education, and Escapism - to the consumption of experiences at heritage tourism sites (Hayes and McLeod, 2007; Juroski, 2009; Mehmetoglu and Engen, 2011; Radder and Han, 2015; Suntikul and Jachna, 2016). Pine and Gilmore's model is also used by recent research on technology-enhanced heritage experiences (Jung, tom Dieck, Lee, Chung, 2016; Lee, Lee, and Ham, 2013). In line with Pine and Gilmore's model, the capacity to address cultural heritage tourists in more than one of the four dimensions can provide a strong experiential value.

Starting from this background, the purpose of this paper is to advance current understanding and practice in relation to the use of smart technologies for the enhancement of cultural heritage experiences at tourism destinations. In particular, the paper raises the need to consider how these technologies can support the intensification of all the four experience dimensions identified by Pine and Gilmore (1998) in relation to an extended perspective of the visitors' experience including pre-visit, onsite and post-visit stages (Neuhofer et al., 2012; 2015). In this view, the paper examines a sample of best practice examples of smart technologies for cultural heritage sites by considering their application in relation to different types of technologies, stages and dimensions of the experience. Starting from the results of the analysis, a framework is presented, which considers the use of different smart technologies in relation to the pre-, during, and post-visit stages for intensifying all the potential dimensions of the visitors' experience at heritage sites. The pilot testing of the framework at a cultural heritage site provides insights into the opportunities to use a combination of applications for facilitating and enriching the cultural visit at the destination according to a multi-stage and multidimensional perspective of the heritage experience.

\section{Theoretical Background \\ Smart technologies at tourism destinations: enhancing cultural heritage experiences}

The development of a smart perspective together with the proliferation of Information and Communication Technologies (ICTs) in all 
the contexts of human activities have encouraged the diffusion of technology also in the tourism sector (Koo, Gretzel, Hunter and Chung, 2015), giving rise to the Smart Tourism concept. Although there is still a lack of definitional clarity related to this term (Buhalis and Amaranggana, 2014; Gretzel, Sigala, Xiang and Koo, 2015), smart tourism encompasses three main components (Gretzel et al., 2015): smart destinations, smart experience, and smart business. In particular, the extensive use of ICTs can support: a) efficiency and sustainability in the destination aspects; b) the enrichment and personalization in the tourism experience aspects; and, c) the introduction of innovations in the aspects related to tourism business. Boes, Buhalis and Inversini (2015, p. 394) conceptualize Smart Tourism Destinations as "places utilizing the available technological tools and techniques to enable demand and supply to co-create value, pleasure, and experiences for the tourist and wealth, profit, and benefits for the organisations and the destination". Lamsfus, Martín, AlzuaSorzabal, and Torres-Manzanera (2015) stress the role of Intelligent Systems in travel and tourism as the basis to evolve a certain destination into a Smart Destination. These represent next generation information systems, such as recommender systems, context-aware systems, autonomous agents searching and mining Web resources and Ambient Intelligence, which promise to supply tourism consumers and service providers with more relevant information, greater decision-support, mobility and ultimately, more enjoyable tourism experiences. In their study on European Smart Cities, Buonincontri and Micera (2016) show how new technologies are able to support the tourism experience co-creation among tourists and tourism service providers in a Smart Destination. The smart approach at destinations provides the needed technological tools and infrastructures to bridge the gaps between the physical world and the digital realm in the space and between different stages of the tourism experience process in the time (Neuhofer et al., 2012). These advancements are becoming essential not only for the competitiveness of the destination as a whole, but also for tourism services providers that are confronted with the challenges related to the development of a smart approach to be competitive (Buhalis and Amaranggana, 2014).

In order to be considered 'smart', the technologies implemented to enhance tourism experiences for visitors have to own important requirements. Neuhofer et al. (2015) consider essential that smart technologies are able to aggregate information, allow ubiquitous mobile connectedness, and provide real time synchronized information. The aggregation information refers to the collection of a big amount of information on tourists during all the experience process, which supports the personalization of services based on their needs. Ubiquitous mobile connectedness refers to the fact that smart technologies are portable and accessible by anyone, anywhere and at any time. Ubiquity of technology allows high levels of interaction between the tourism service providers and tourists wherever they are, both on site or off site. Another essential prerequisite for smart technology is real time synchronization, which completely changes the way the information is processed. Through real time synchronization, information is not limited to the moments of face-to-face interaction between tourism service providers and tourists, but is collected and updated at every moment. A similar feature of smart technologies allows to constantly adapt the experience according to the new information acquired by the tourist.

Information aggregation, ubiquitous mobile connectedness and real time synchronization are supported by a range of technologies, allowing the creation of interactive, personalized, and dynamic tourism experiences (Neuhofer et al., 2015). Among them, a key technology is the Internet of Things (IoT), which refers to the pervasive presence in the real environment of technological objects that are able to interact and cooperate with each other to achieve common goals (Want et al. 2015). RFID tags, sensors, QR codes, or NFC tags are interconnected through the Internet and allow users to access to information about tourism resources or points of interest, or to easily manage tourists' reservations. IoT adds value to the tourism experience by creating a smart technological environment that connects the real world and the digital realm (Atzori, lera and Morabito, 
2010; Buhalis and Amaranggana, 2014; Gretzel et al., 2015). Smart tourism applications increasingly feature mixed reality, which includes Virtual Reality (VR) and Augmented Reality (AR). VR allows to increase the human perceptions about the real environment through technology, and enables visitors to have an experience in a different place and a different time. AR is a blending of virtual and real objects in order to augment the meaningfulness of an environment located in proximity of the user position (Graham and Zook, 2013). In addition, websites are increasingly developed according to a smart approach. New, advanced websites differ from traditional ones since they provide also interactive maps for obtaining personalized previsit information, links to social media for supporting socialization, interactive videos with VR for user engagement, customizable itineraries, games, and reservation services for active participation of users (Buhalis and Wagner, 2013).

As previously stated, smart technologies can be accessed by tourists anywhere and at any time. Although the traditional personal computers still play an important role, mobile devices (smartphone and tablets) are the most used tools, especially in the on-site stage of the visit. The growing diffusion of mobile devices has recently opened new ways for the destinations to connect with their tourists thanks to the possibility to provide mobile applications (apps) that can be downloaded and installed on tourists' devices. The most innovative tourism apps, which adopt a smart approach, are able to provide location-based services, AR systems, services to assist tourists with navigating, finding locations, retrieving information and making reservation, games and entertainment services, social activities and photos sharing (Lamsfus, Grün, Alzua-Sorzabal and Werthner, 2010; Neuhofer et al., 2012; Wang and Xiang, 2012). In this way, mobile devices have the capability to link users to remote information repositories, exchange location-based data and spread social information, revealing new experiential opportunities (Dickinson, Ghali, Cherrett, Speed, Davies and Norgate, 2014; KennedyEden and Gretzel, 2012). Recently, a new generation of devices has emerged related to smart technologies, notably wearable devices. These include head-mounted displays (e.g. Samsung Gear, Oculus Rif), smart glasses, smart wristbands, smart gloves, and smart watches. They are characterized by a symbiosis of technology and human actions; they may provide to tourists $A R$ and VR systems and information overlay, and may allow travel reporting with first-person view and instant navigation. Wearable devices, therefore, are able to define a simpler and stronger relationship between technology and tourist, becoming a fundamental tool in mediating and shaping the tourism experience (Tussyadiah, 2013; Tussyadiah, Jung and tom Dieck, 2017).

Among tourism destination resources, cultural heritage sites and attractions, including museums, monuments, art galleries, theatres, archaeological, historical, and religious sites, cultural festivals and events, can significantly benefit from the application of smart technologies. The advent of smartphones and wearable devices has fuelled the development of a variety of applications to enrich visitors' experiences, support the marketing of cultural institutions and destinations and contribute to extend their audience reach (Bakshi and Throsby, 2012; Chung et al., 2015). For example, AR systems can help visitors to relive historic life or architecture by revealing ancient buildings as 3D objects, which are overlaid on the actual monuments (Kourouthanassis et al., 2015; Vlahakis, loannidis, Karigiannis, Tsotros, Gounaris, Stricker, Gleue, Daehne and Almeida, 2002). Further, they provide opportunities to explore unknown areas in an enjoyable and interactive manner and to facilitate learning processes through the integration of AR gaming (Angelopoulou et al., 2012; Han, Leue and Jung, 2014; tom Dieck and Jung, 2015; tom Dieck, Jung, and tom Dieck, 2016; Tscheu and Buhalis, 2016). Research in this field also emphasizes the potential of VR as a tool for cultural heritage marketing, education and preservation (Huang et al., 2013; Guttentag, 2010; Jung et al., 2016, 2017; Pantano, 2011). Recently, the application of wearable devices in this context, in particular smart glasses (e.g. Google Glass) and head mounted displays (e.g. Samsung Gear, Oculus Rift), supports the 
creation of new immersive virtual encounters between visitors and cultural attractions (Leue, Jung, and tom Dieck, 2015; tom Dieck, Jung and tom Dieck, 2016; tom Dieck, Jung and Han, 2016). In one of the first studies on the use of these cutting-edge devices in the cultural heritage context, Leue, Jung, and tom Dieck (2015) reported on art galleries visitors' learning experiences with Google Glass. Their analysis revealed that these wearable applications can enhance the knowledge and understanding of paintings, support the personalization of the cultural route among exhibits and improve visitors' engagement in the experience.

However, the growing number of studies and projects relating to the use of smart technologies in the cultural tourism domain mostly focus on the use of the different applications for supporting cultural visitors during the physical, on-site visit (Kuflik et al., 2015). By contrast, the cultural heritage experience is not limited to the time spent onsite; it begins before the actual visit and continues with memories and reflections after the visit (Kuflik et al., 2015; Marty, 2007; Mclntosh, 1999). Accordingly, when addressing the technological potential in this context, it has to be considered that the cultural heritage experience develops throughout an extended process, which is composed by pre-visit, onsite and post-visit stages. Smart technologies, indeed, are able to positively enhance the overall journey of cultural visitors and the different potential components of the cultural heritage experience (Bakshi and Throsby, 2012; Kuflik et al., 2015; Neuhofer et al., 2012; Jung et al., 2016; Jung and tom Dieck, 2017).

\section{Cultural heritage experiences: a multi- dimensional perspective}

In the last years, an experience perspective has been increasingly emphasized in the management of the relationship between visitors and cultural heritage resources, as a way for these tourism attractions to successfully cope with current market changes. Confronted with the changing demand and cultural consumption patterns, the cutbacks in public budgets, the growing emphasis on value creation and innovation, cultural heritage institutions (i.e. museums, archaeological parks, theatres, etc.) are increasingly concerned with achieving enhanced performance, also by adopting a more visitororientated approach that emphasizes demand preferences and quality of the cultural experience (Calver and Page, 2013; Camarero, Garrido and Vicente, 2012; Bakshi and Throsby, 2010).

Although consensus on the definition of visitors' experience at heritage sites is still lacking (Landorf, 2009; Sheng and Chen, 2012), recent years have witnessed a proliferation of studies on the experiential consumption of cultural heritage resources, primarily with regard to museums (Buonincontri et al., 2017; Falk and Dierking, 1992; Jurowsky, 2009; Mehmetoglu and Engen, 2011; Radder and Han, 2015; Sheng and Chen, 2012). Research in this area has explored the different dimensions that can positively influence the experience at heritage sites, mostly building on the model proposed by Pine and Gilmore (1998). This fundamental contribution laid the foundation of the experience economy and introduced four dimensions of experiences, based on the combination of active or passive customer participation and customer's connection with the environment in terms of absorption (mental involvement) or immersion (physical or virtual immersion). In the first realm - Entertainment the customer passively absorbs the experience through his/her senses; sensory stimuli cause interest, wonder and excitement and as a result influence memory for a lasting effect. Esthetic experiences result from higher levels of customer immersion combined with low levels of customer participation. Esthetic experiences, which are strongly dependent on the customers' mood, imagination and perceptions, involve the appreciation of a pleasant environment and can be influenced by the tangible and intangible elements of the heritage context. The third dimension - Education requires customer's absorption and active participation. It involves cognitive engagement of the customer in the interactive experience. Finally, Escapism is characterized by an active participation and immersion in a way that one can lose oneself in the experience and escape from the ordinary life. Escapism involves the senses and emotions of customers, giving rise to highly memorable experiences where the 
individual takes part in enhancing their own experience.

This typology of experience dimensions has been widely used in theoretical and empirically studies aimed at understanding tourism experiences (Oh, Fiore and Jeoung, 2007; Quadri-Felitti and Fiore, 2012; Stamboulis and Skayannis, 2003). It has also been used with regard to tourism experiences at heritage sites. According to Mannell and Iso-Ahola (1987) and Slater (2007) (cited by Radder and Han, 2015), escapism is the core motivation for visiting a heritage site, followed by the education dimension. The study by Jurowsky (2009) found that visiting art galleries may be considered an education experience and that this activity strongly affects the visitors' emotions. It also showed that visiting cultural and historic sites may be considered an aesthetic experience and that this activity is strongly related to the total involvement of visitors through their sight, sound, touch, smell and taste. Hayes and McLeod (2007) argue that an experience-based design of heritage trails can provide the opportunities to enhance visitors' engagement with authentic, emotional and spiritual experiences that satisfy across all the four realms. Focusing the attention on the experience visit of museums, Mehmetoglu and Engen (2011) investigated how the experience dimensions influence the visitors' satisfaction. They found that only education and aesthetic have a strong effect on the visitors' satisfaction. More recently, Radder and Han (2015) conducted a survey on three heritage museums in South Africa, individuating that the dimensions of education and entertainment may be combined in the edutainment dimension. Furthermore, they found that edutainment is the most important experience realm in determining visitors' satisfaction, revisit intention and word-of-mouth intention. The relevance of education and entertainment dimensions is in line with the museum goals of educating and entertaining visitors declared by ICOM (2007). Suntikul and Jachna (2017) employ Pine and Gilmore's model to understand the role of different realms of experience in the perception of the experiential values of Macao's Historic Centre and the heritage sites therein. Their study found that the Historic centre as a whole was perceived as most strong in the aesthetic and entertainment dimensions, while most of the individual sites were characterized by high ratings in the aesthetic realm, followed by escapism.

Recent research has also employed these four dimensions in relation to the application of new technologies to heritage experiences. Lee et al. (2013) investigated the influence of social presence in smartphone applications on the dimensions of tourists' experience and satisfaction at cultural heritage attractions in Korea. Their study found a significant relationship between presence and entertainment and escape experience. Lee, Chung and Koo (2015) showed how AR applications play an important role in enhancing aesthetic experience of tourists at heritage sites. Jung et al. (2016) individuated that mixed reality (AR and VR) applied at cultural heritage sites is a strong predictor of the four dimensions of experience economy. Their study reveals that except for aesthetic dimension, the other dimensions - especially entertainment - have a significant influence on cultural heritage visitor experience, which consequently affects tourists' intention to revisit visitor attraction.

Empirical studies, therefore, demonstrate the validity of the four dimensions identified by Pine and Gilmore in describing tourism experiences at cultural heritage sites. Research also reveals that different cultural heritage experiences can be related to different dimensions: visiting a cultural site may be more related to aesthetic and education dimensions, acting on emotions and sensory stimuli of visitors, while visiting a museum mainly affects education and entertainment dimensions. The importance of education and entertainment in successful and memorable cultural heritage experiences reveals that these experiences are able to stimulate both the cognitive and emotive processes of visitors, generating a sense of pleasure and, in the meantime, positively impacting on the rational considerations of individuals (Addis, 2005).

From the analysis of extant research, it appears that approaches to enhancing cultural heritage experiences, including the technology- 
based ones, are not always able to intensify all the four experience dimensions. This can limit their potential in creating truly rich experiences for visitors. According to Pine and Gilmore (1998), in fact, the richest experiences - those being most satisfactory and memorable encompass aspects of all four dimensions, although different levels of emphasis may occur. Therefore, more research is needed the creation of rich and memorable experiences in the cultural heritage context by leveraging the potential of smart technologies.

\section{Methodology}

Starting from this background, an analysis of best practices relating to the application of smart technologies in the cultural heritage context has been performed in order to understand if and how current smart technologies support the integrated multi-stage and multi-dimensional perspective of cultural heritage experience. In particular, the analysis was aimed at understanding the capability of these technologies to support the intensification of all the four experience dimensions identified by Pine and Gilmore (1998) in relation to an extended perspective of the visitors' experience including pre-visit, on-site and post-visit stages (Neuhofer et al., 2012; 2015). Best practice is a concept widely used in the business context to indicate successful industry cases that can be considered as reference models (Hallencreutz and Turner, 2011). Individuation of best practices relating to the application of smart technologies in the cultural heritage context is fundamental to gather the necessary information and successful actions to understand how smart technologies may enhance cultural heritage experiences at tourism destinations (Neuhofer et al., 2015).

Given the purpose of the analysis, best practices have been analysed in relation to their focus on one or more of the stages of the experience as well as to their orientation to intensify one or more of the four experience dimensions previously identified (entertainment, education, esthetic, escapism). The analysis has been carried out by means of a desk research and collecting secondary data.

Following Buhalis and Wagner (2013), the identification of best practices was mainly web- based as the information is available online. Online search was conducted through the main search engine (i.e. Google) and smartphone platform websites iTunes and Google+. The online search was supplemented by discussions with industry Italian experts (IT companies, cultural heritage managers, tourism operators) conducted in the period September 2015 - June 2016. Heritage managers (museums, cultural sites) contributed to the analysis by indicating some cultural institutions that are regarded as forerunners of technological innovation in the sector, paving the way to the application of the most advanced and emerging technology for heritage enhancement and audience development. These include the National Gallery of London (UK), the Cleveland Museum of Art (USA), the Hermitage Museum (Russia), the Tate Modern Museum (UK). These experts also reported on some national sites with projects involving the application of smart technologies (i.e. Matera, Royal Palace of Caserta, Museo Galileo of Florence). In parallel, IT companies involved in the discussions provided useful information about the recent evolution and application of latest mobile AR technologies and VR devices.

In the process of identifying the best practices to be analysed, only smart technologies that refer to specific cultural heritage context (museums, cultural sites, historical centres, archaeological parks, etc.) were taken into account. Moreover, technologies under development that were still in the pilot testing stage were excluded. This ensured to analyse only technologies that are effectively available for visitors. Finally, mobile apps without smart requirements (ability to aggregate information, allow ubiquitous mobile connectedness, and provide real time synchronized information for interaction, socialization, personalization and active participation) were not considered, since standard mobile apps that support the cultural visit are now almost universally widespread. Also general apps used during cultural heritage experiences, such as Google Maps, Facebook, Twitter, TripAdvisor, Yelp and Skype were excluded from the analysis. As a result, 25 best practices have been individuated, which are described in Table 1. 
Enhancing Cultural Heritage Experiences with Smart Technologies: An Integrated Experiential Framework.

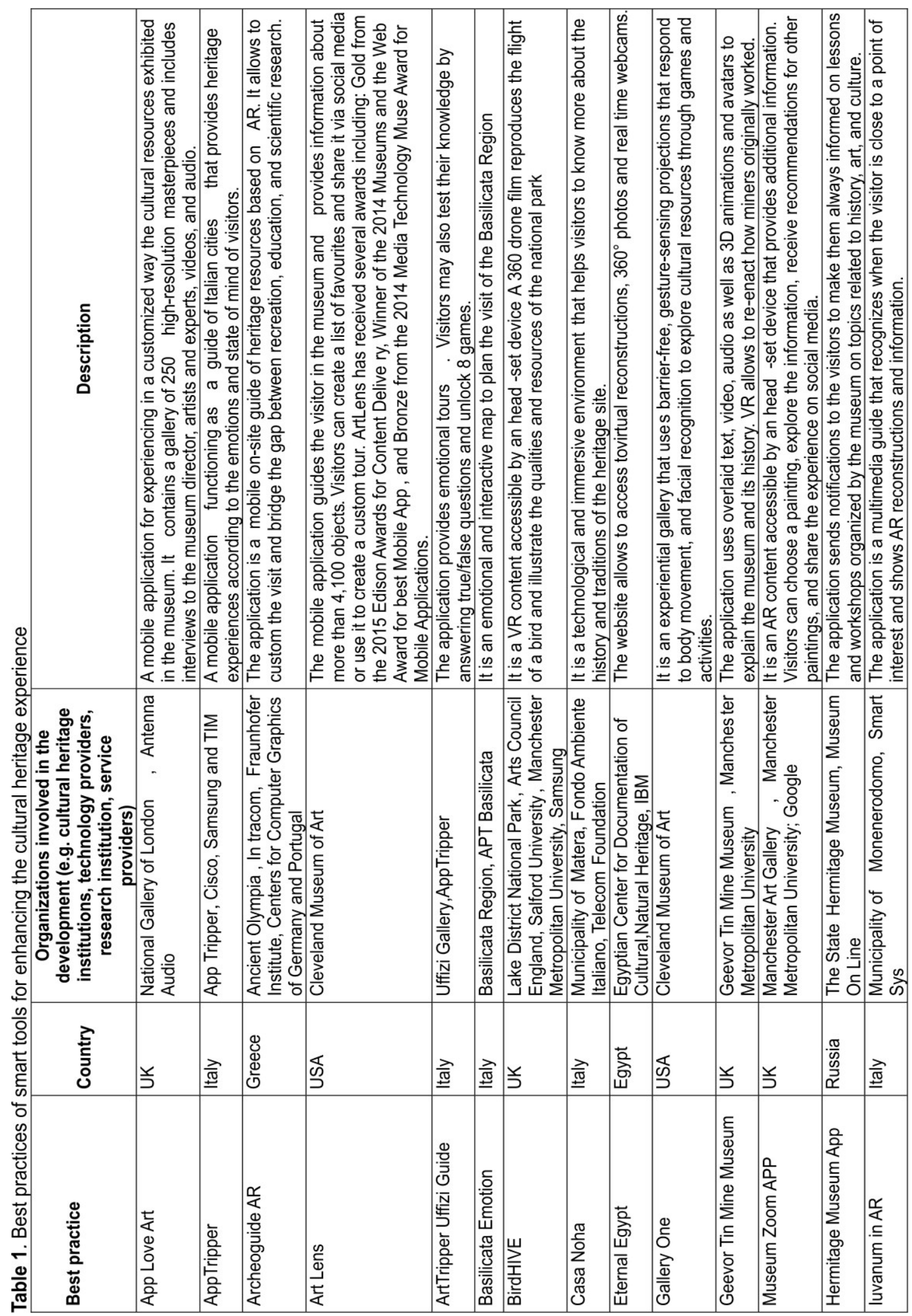




\begin{tabular}{|c|c|c|c|c|c|c|c|c|c|c|}
\hline 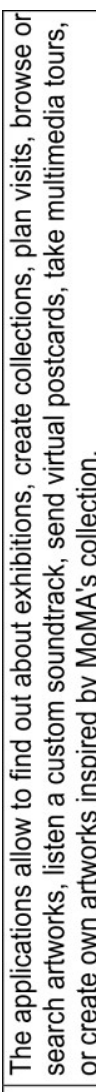 & 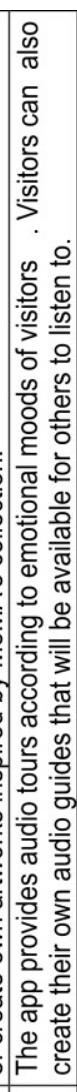 & 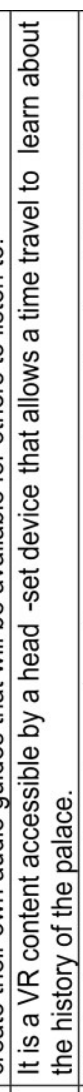 & 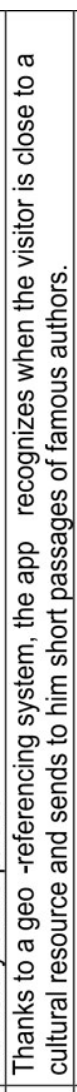 & 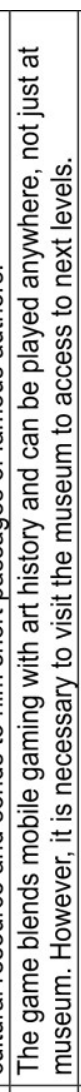 & 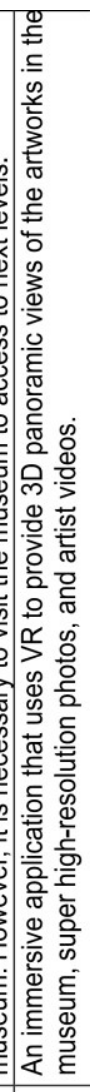 & 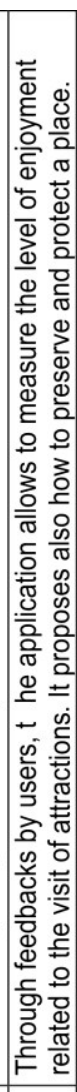 & 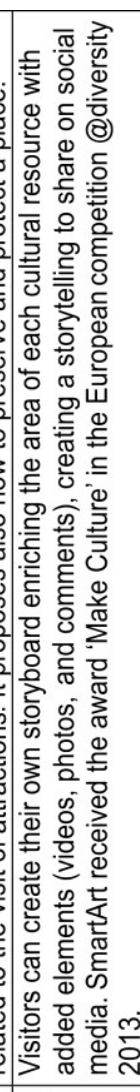 & 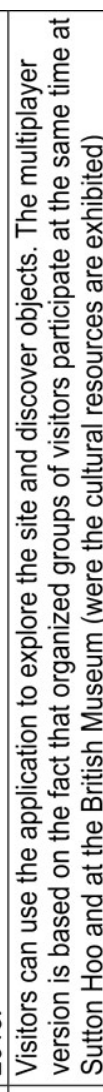 & 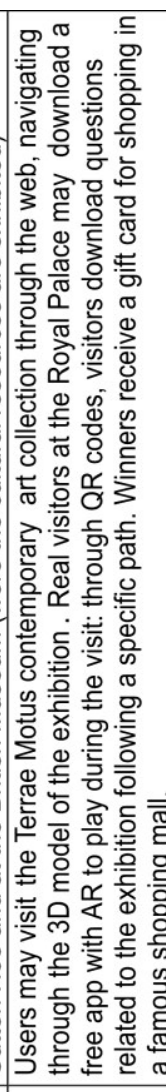 & 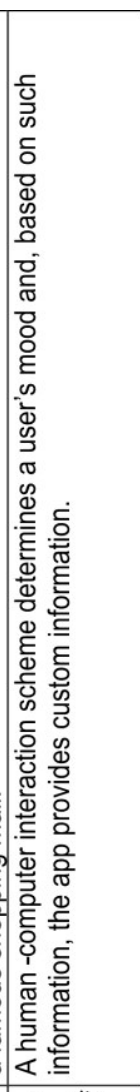 \\
\hline 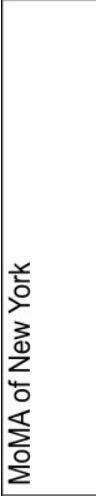 & 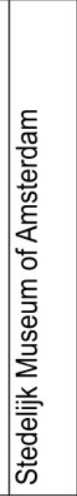 & 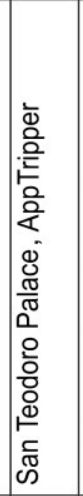 & 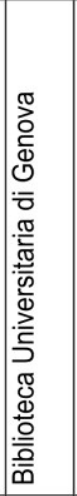 & 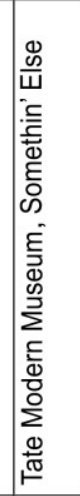 & 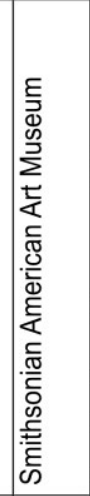 & 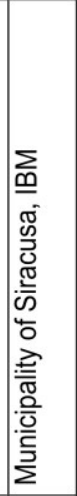 & 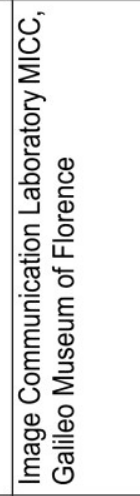 & 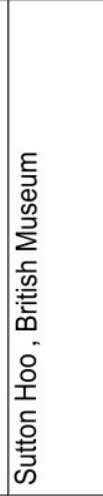 & 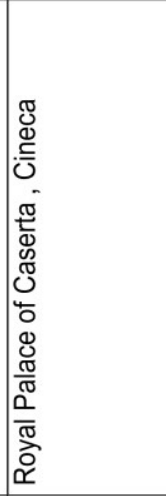 & 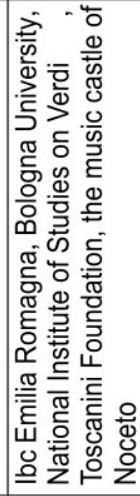 \\
\hline $\begin{array}{l}\text { ग } \\
\text { }\end{array}$ & $\begin{array}{l}\text { 음 } \\
\text { 뜸 } \\
\text { 오 }\end{array}$ & $\stackrel{\text { बे }}{\underline{\pi}}$ & 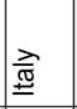 & $\stackrel{y}{د}$ & Фి & $\stackrel{\text { IJ }}{ \pm}$ & 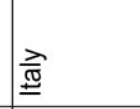 & כૅ & $\cong$ & 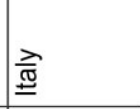 \\
\hline & $\begin{array}{l}\frac{0}{2} \\
\frac{0}{2} \\
\frac{0}{2} \\
\frac{0}{2}\end{array}$ & 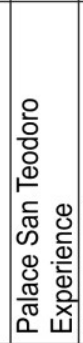 & $a^{\pi}$ & 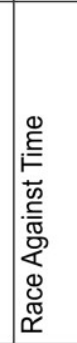 & 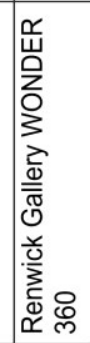 & 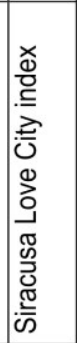 & & 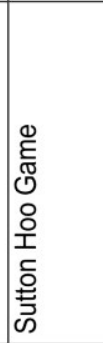 & 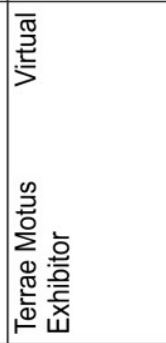 & 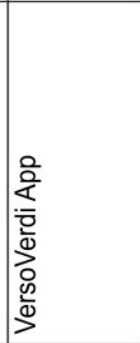 \\
\hline
\end{tabular}


Where possible, the technologies were downloaded and used so that their role in enhancing the cultural heritage experience could be understood from a user perspective. Otherwise, the information and feedback from users available online was used to analyse the technologies. The criteria for the analysis were defined on the basis of the findings of the literature review. In detail, the following features of each technology were examined:

1. The specific technology (typology) used and its general functionalities;

2. The stage of the experience that is supported by the technology;

3. The features of the smart technology in relation to one or more experience dimensions (education, entertainment, esthetic, and escapism).

These features were defined in advance in order to guarantee an objective evaluation (Buhalis and Wagner, 2013). The existence or non-existence as well as the way in which the smart technologies influence the cultural heritage experience have been observed and reported in a table to facilitate the comparison of results.

Table 2. Analysis of the best practices

\begin{tabular}{|c|c|c|c|}
\hline Best practice & Technology/device & Experience stage & Experience dimensions \\
\hline App Love Art & Mobile App & On site & Education \\
\hline AppTripper & Mobile App & On-site & Escapism \\
\hline Archeoguide AR & AR, Electronic guide & On site & $\begin{array}{l}\text { Esthetic - Entertainment - } \\
\text { Escapism }\end{array}$ \\
\hline Art Lens & Mobile App & On site - Off site & Education - Entertainment \\
\hline ArtTripper Uffizi Game Guide & App/Game & On site - Off site & $\begin{array}{l}\text { Education - Entertainment - } \\
\text { Escapism }\end{array}$ \\
\hline Basilicata Emotion & Website & Off site & Escapism \\
\hline BirdHIVE & $\begin{array}{l}\text { VR / Head mounted } \\
\text { display }\end{array}$ & Off site & Esthetic \\
\hline Casa Noha & $\begin{array}{l}\text { Tech. environment } \\
\text { /Immersive videos }\end{array}$ & On site & Education - Esthetic \\
\hline Eternal Egypt & Website & Off site & Education \\
\hline Gallery One & $\begin{array}{l}\text { Tech. environment/ } \\
\text { multitouch screens }\end{array}$ & On site & Education - Entertainment \\
\hline Geevor Tin Mine Museum & $\begin{array}{l}\text { AR, VR/Head mounted } \\
\text { display }\end{array}$ & On site & $\begin{array}{l}\text { Education - Entertainment - } \\
\text { Escapism }\end{array}$ \\
\hline Museum Zoom APP & AR/smart glass & On site & Education \\
\hline Hermitage Museum App & Mobile App & Off site & Education \\
\hline luvanum in AR & Mobile App & On site & Education \\
\hline MoMA Apps & Mobile Apps & On site & Entertainment \\
\hline Mood App & Mobile App & On site & Escapism - Entertainment \\
\hline $\begin{array}{l}\text { Palace San Teodoro } \\
\text { Experience }\end{array}$ & $\begin{array}{l}\text { VR/ Head mounted } \\
\text { display }\end{array}$ & On site & Entertainment - Esthetic \\
\hline PassInversi & Mobile App & On site & Education \\
\hline Race Against Time & Game & On site - Off site & Entertainment - Escapism \\
\hline $\begin{array}{l}\text { Renwick Gallery WONDER } \\
360\end{array}$ & VR & Off site & Esthetic \\
\hline Siracusa Love City index & Mobile App & On site & $\begin{array}{l}\text { Education } \\
\text { Escapism }\end{array}$ \\
\hline SMartART & Mobile App & On site & Entertainment \\
\hline Sutton Hoo game & $\begin{array}{l}\text { Mobile-AR educational } \\
\text { game }\end{array}$ & On site & Education - Entertainment \\
\hline $\begin{array}{l}\text { Terrae Motus Virtual } \\
\text { Exhibitor }\end{array}$ & VR/ AR & Off site & Education - Entertainment \\
\hline VersoVerdi App & Mobile App & On site & Escapism \\
\hline
\end{tabular}




\section{Results and discussion}

Results of the desk analysis of technological tools used to enhance the cultural heritage experience have been summarized in Table 2 . The study of best practices has been developed in relation to the dimensions considered - type of technology used, stage(s) of the experience supported and dimension(s) of the experience enhanced by technologies. It is to be noted that a clear-cut distinction between active and passive participation of users in the technologies examined is not always in place. Smart technologies, in fact, are aimed at supporting the creation of interactive, personalized, and dynamic experiences (Neuhofer et al., 2015); for this reason, a minimum of active participation by users is always proposed.

The analysis of these best practices according to the established criteria shows that smart technological efforts in this context are mostly focused only on one of the stages of the heritage experience, notably the onsite stage. This confirms the gap highlighted by Kuflik et al. (2015) in the application of technologies in the heritage domain and the related need to link the pre-visit stage, onsite stage and postvisit stage of the experience.

Looking at the specific tools in use, the analysis highlights that most of the best practices are represented by mobile apps. Their widespread use is related to its possibility to be downloaded by visitors on their own devices and to their customization that allows to visitors to access only to the information they need. As expected, these apps are almost exclusively used on site, supporting an enhancement of the cultural heritage experience only at the moment of the actual visit. The use of other technologies and devices is still in an early stage, also due to their relatively recent emergence, as in the case of wearable devices. Notable exceptions include the tool developed by the Geevor Tin Mine Museum in Cornwall in collaboration with the Manchester Metropolitan University that combines augmented reality and virtual reality with the support of Samsung Gear VR device. In 2015, the Geevor Tin Mine Museum in Cornwall launched a unique experience for the enhancement of its exhibition, which was recognised by UNESCO in 2006 as a World Heritage site. The approach underlying this tool is oriented to reflecting the international value and significance of Geevor's remarkable landscape and combines multiple technologies to enhance the pre-during and post-visit experience (Jung and tom Dieck, 2017). The Samsung Gear VR device is used also by the Italian site Palace San Teodoro, a monumental building that reflects the standards of neoclassical architecture. An immersive VR experience has been developed to allow visitors to enjoy the reconstruction of the city in which the palace is located together with a music symposium of the 18th century, immersing them into the historic atmosphere and artistic charm of this time.

Looking at the examined tools with regard to the most emphasized experience dimensions, it clearly emerges that they are mostly oriented to intensify and support education and entertainment, as expected. Numerous studies have demonstrated the potential of new technologies, including $A R$ and VR, for educational aims in the heritage context (Guttentag, 2010; Jung et al., 2016; Leue et al., 2015; Mortara, Catalano, Bellotti, Fiucci, HouryPanchetti and Petridis, 2014; tom Dieck et al., 2016). Often, smart technologies affect both the dimensions at the same time, allowing edutainment. The Race against time tool developed by Tate Modern is a remarkable and known best practice in relation to the enrichment of cultural experiences through the leverage of entertainment by technological applications. Race Against Time is a game for iPhone or iPod Touch launched in 2011, where the user plays as a chameleon, travelling through the history of modern art, on naming its references as they pop up. Interestingly, this tool can be played anywhere, not just at Tate Modern, but opening the game inside the Tate (location is ensured by smartphone GPS) will unlock "Turbo Mode", which lets the chameleon use a supercharged jump and kill enemies with its tongue. Once players beat levels of art history, they also have access to an "achievements" section that compares the works seen in the game to actual paintings in the Tate's collection. 
The two applications developed by the Cleveland Museum of Art are among the most interesting best practices that are strongly oriented to edutainment. The Gallery One experience consists of ten interactives: the Collection Wall, three interactives designed for children and located in Studio Play, and six interactive displays (lenses). The six interactive stations collectively known as "lenses" feature touch screens that allow visitors to discover information about related artworks placed nearby, as well as engage in unique interactive activities. Edutainment experience is well recognized by users, as the following comments on the gallery website show:

"[...] was really cool. Had to critically look at how figures were positioned. Nice to have feedback from object and adjust accordingly. You literally play with the art".

"I liked watching the Stories Through Time, nice because I didn't have to do anything, like watching YouTube video and I also got to learn something about art too".

While all lenses share a similar home screen layout, each possesses its own theme related to the artwork on display. Information is provided in a question and answer format, and hotspots allow visitors to find out additional information by touching specially designated areas. Additionally, the touch capability of the lenses allows visitors the opportunity to have interactive viewpoints that would not be possible in a traditional gallery setting, such as a view of the back of a bowl or the opportunity to zoom in on a painting. The "Painting" Lens, for example, includes, among others, the Make Your Mark application, providing visitors with three abstract painting techniques, represented by different objects from the museum's collection, and inviting to become a virtual abstract painter by utilizing the techniques of pour, drip, and gesture to create art of their own. In the Remix Picasso Lens, the visitor is invited to re-arrange "pieces" of a composition in order to illustrate the interplay between flatness and depth in paintings, while the Discover Tempera Lens serves to illustrate each of the five stages of the tempera painting process. Gallery One has recorded over 9,500 users in the period 2013-2014, with more than 3,700 tours started and over 25,000 objects saved to ArtLens from the wall. In the same period about 2,500 interactions with the lenses was recorded, with nearly $60 \%$ of visitors interacting with the lenses in Gallery One (Alexander, Barton and Goeser, 2013).

The use of smart technologies, in particular VR applications, can affect also the aesthetic dimension of the heritage experience, allowing high levels of visitors' immersion in virtual worlds (Guttentag, 2010; Jung et al., 2016). In many of the examined VR experiences, such as Wonder 360 of the Smithsonian American Art Museum, BirdHIVE, SanTeodoro Experience, visitors are immersed in an activity or environment, but having little effect on it. In these cases there appears to be a strong emphasis on the (virtual) experience of the detailed features of the heritage site and the sights, sounds that surround it. By contrast, some of the examined technologies, including websites, apps, VR, are used so as to support a more active participation and immersion of visitors, yielding a stronger escapist experience. This is the case, already mentioned, of the Race against time by Tate Modern, which allows users to play as a chameleon and travel through the history of modern art. In other cases, the active participation of users is related to their involvement in the personalization of the experience according to their emotional states or mood. Though not "Acting in a play, playing in an orchestra, or descending the Grand Canyon" (Pine, Gilmore, 1998, p. 102), cultural visitors and tourists are connected to their experience through their involvement in the identification or imagination of a particular emotion or feeling, which can strongly affect the way they actually experience the site in that particular moment.

\section{A framework for smart and memorable cultural heritage experiences \\ The dimensions of the framework}

Starting from this background, a framework is proposed that aims at transforming the traditional visit at cultural heritage sites into a memorable experience for tourists through the use of smart technologies. The framework is developed on the basis of the insights and lessons gained from the previous analysis of studies and best practices and is characterized by the following distinctive features: 
i. the recognition of an extended visitors' process including pre-visit, visit and post-visit stages, according a multi-stage view of the tourism experience and visitors' experience at cultural heritage sites;

ii. the application of technologies to facilitate and enrich the overall experience, from the anticipatory stage, through the on-site stage, to the post-visit stage;

iii. the combination of different types of technologies to exploit their synergies in producing a rich and memorable experience that combines all the four dimensions of entertainment, education, escapism and aesthetics identified by Pine and Gilmore (1998).

In more detail, the framework includes three interrelated components of a smart technologyenhanced experience at cultural heritage sites (Figure 1): offsite, on-site, and online.

The first element relates to the pre-visit stage of the visitor's journey, where expectationformation, decision-making and anticipation occur (Aho, 2001; Gretzel, Fesenmeier, and O'Leary, 2006). In this stage, the use of smart technology is aimed at influencing potential visitors' awareness of the cultural heritage site or attraction, interest for visiting it and anticipation of the experience. It is strategically directed to positively affect behavioural intention to visit the site. To this end, the framework leverages the potential of virtual reality systems as effective destination marketing tools (Guttentag, 2010; Huang et al., 2013; Neuhofer et al., 2012; Jung and tom Dieck, 2017; Jung et al., 2017; Tussyadiah, Wang and Jia, 2017), which enable visitors to experience tourism sites before their journey starts. In the proposed framework, this component is conceived to support an immersion of potential visitors into the heritage experience before the actual immersion onsite. In particular, this offsite component is supported by a "cinematic" VR experience with wearable computing devices, notably with a head-mounted display. An immersive virtual environment that recreates the heritage site allows potential visitors to explore it, get inspiration, interest and emotional involvement. The "cinematic" feature of the VR experience includes an immersive trailer shot at the heritage site with $360^{\circ}$ cameras. This cinematic effect is designed so as to intensify the aesthetic dimension of the virtual heritage experience: the use of latest VR devices together with a stereoscopic 3D vision of the

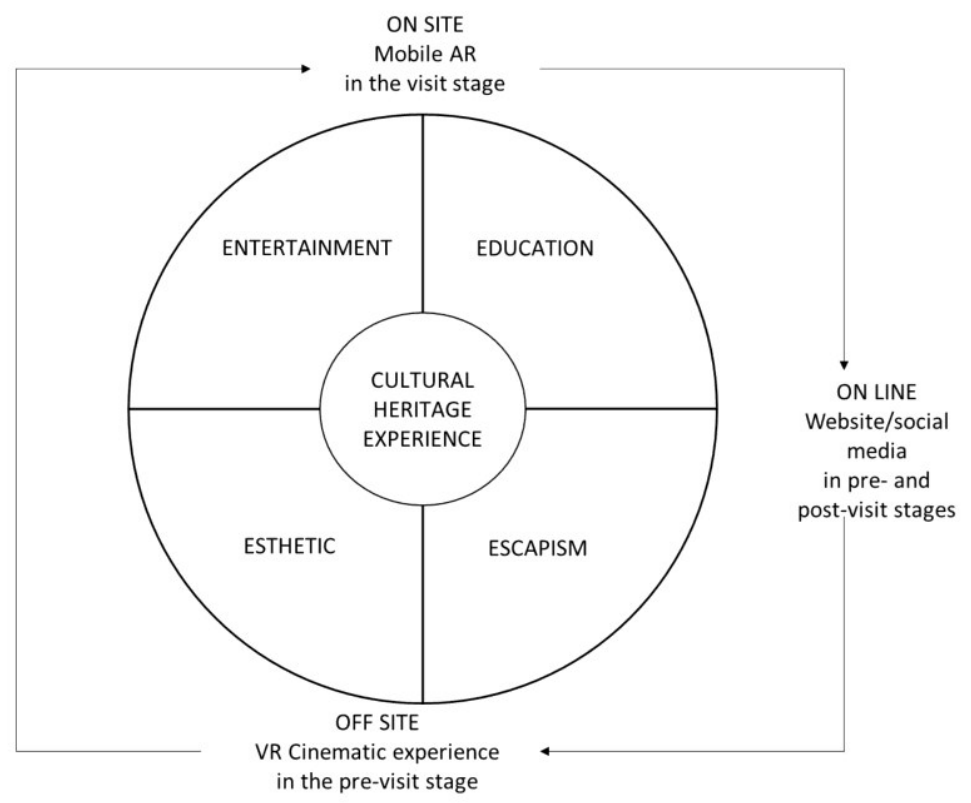

Figure 1. The proposed framework (our elaboration based on Pine, Gilmore (1998) and Neuhofer et al. (2012)) 
site from its interiors allows a completely immersive and very realistic connection with the "future" experience at the real site, that fuels imagination, esthetical suggestion and fascination of virtual visitors.

The second component represents the "consumption" stage at the actual encounter, when the visit takes place at the heritage site. In this stage, the framework exploits the latest mobile AR technology to facilitate and enrich the visit experience on-site. In order to support cultural tourists in this stage a mobile AR application is conceived to facilitate navigation, information search, learning in an enjoyable way. Given the important role of technology in facilitating learning in this context, the application used for the onsite stage is primarily expected to intensify both the education and entertainment dimensions of the heritage experience. As shown by the analysis, smart mobile applications can support very well these dimensions in relation to a more active or passive participation of the visitors during the experience, from an intensification of the multisensory experience related to the heritage site, to their active involvement in gaming and other edutainment activities.

The third component is a transversal one and relates to both the pre-visit and the post stages of the cultural journey. In this case, technology is used for facilitation (find the site, manage itinerary), information search (search restaurants, hotels and other cultural heritage sites nearby), planning of the visit before their journey as well as for re-experiencing, further documentation, and sharing of the experience in the post-visit stage. This is realized through a website providing a touchpoint with travel information, contents on the heritage site and share the visit experience through social media features. In the proposed framework this technology is supposed to enhance the experience by intensifying the possibilities for education and escapism. The website supports the educational experience by providing users extra-contents for deepening the knowledge of the heritage site and continue the visit in the online dimension. With regard to the escapism dimension, the website is meant to offer visitors an additional possibility to immerse in the experience, customize it and strengthen its emotional connection. Indeed, as revealed by the analysis of previous studies and best practices, the emotions and state of mind of visitors represent an increasingly relevant aspect of the heritage experience that can be enhanced with smart technologies.

\section{Pilot testing of the framework}

The proposed framework with its technological applications has been applied and pilot tested at the cultural heritage site of the Fontanelle Cemetery, an ossuary located in a cave in the tuff hillside in the city of Naples (Italy). This site is associated with a part of the history and folklore of the local population. It gathers the remains of thousands of anonymous corpses (skulls) since the 16th century and it has been the location of a spontaneous cult of devotion to these unnamed dead. It has recently undergone restoration as a cultural site and can be freely visited. With regard to the offsite dimension of the cultural heritage experience, an immersive environment was developed with the VR system Oculus Rift. Through this wearable device, potential visitors could get virtually immersed in the representation of the Cemetery, watching real actors telling its story in the form of a cinematic trailer. The virtual environment and the actors play immersed in a suggestive scenario, where the details, sights and sounds of the site interiors can be experienced in a very realistic way. The VR system was located at a metro station near the historic centre of the city to intercept potential visitors and motivate them to visit the actual heritage site. At the end of the cinematic VR experience, they were invited to connect with the mobile AR application and the website to continue their journey towards the Cemetery. Both these applications supported the planning of the actual visit by providing information to locate the site in the city, manage itinerary, and find restaurants, hotels and other cultural heritage sites nearby. When immersed in the physical on-site space of the Cemetery, visitors were assisted by the mobile app in finding their way easily into the site, which can be difficult to navigate due to its quite dark atmosphere. The mobile app was meant also to facilitate the learning process in an enjoyable way, acting on the education and entertainment dimensions. It provided cultural visual and audio contents relating to the historical, anthropological, 
religious and cultural significance of the Cemetery together with some AR contents aimed at enriching the experience on-site. These include the projection of digital contents relating to some 'characters' of the site (e.g. 'legendary' ghosts, the voices of dead, the prayers by devotees). For example, the digital image of a 'famous' ghost (named 'the captain') appears on the screen of the mobile devices to tell its legend to visitors approaching the area of the site where its skull is located. Visitors could activate the contents from their smartphones by framing the markers placed at some points of interests into the Cemetery. Finally, the online component was supported by a website with further documentation on the site and social media features as a touch point for re-experiencing, discussing and consolidating the experience and post-sharing it. The structure of the website emphasizes further learning needs of actual visitors by providing extra contents for deepening its knowledge. Among these, it also provides the possibility to experience the authenticity of the heritage site through different perspectives of other people and their specific relation with the site, including a famous actor, an artist, a philosopher, a moviemaker. This is also supplemented by the possibility to share the emotional experience of the cultural site, allowing to the users to connect with others through links to social media.

\section{Conclusions and future perspectives}

The paper is framed within the current debate on the use of smart technologies for the enrichment of experiences at the destination, focusing on the visitors' experience at cultural heritage sites. The creation of rich and memorable tourism experiences with new technologies is a strategic challenge for destination competitiveness and smart development (Buhalis and Amaranggana, 2014; Gretzel et al., 2015 Neuhofer et al., 2012; Tussyadiah, 2015; Tussyadiah et al., 2017). Further, visitors experience has become an important notion in cultural heritage marketing. Enhancing visitors' experiences represents an important goal for heritage managers when designating their strategies (Bakshi and Throsby, 2012; Chen and Chen, 2010; tom Dieck and Jung, 2017). In this direction, a primary challenge is related to the adoption of an extended perspective for the application of smart technologies to cultural heritage experience that exploits their potential in enhancing and supporting all the different stages of the visit experience, not only the onsite stage (Kuflik et al., 2015). Moreover, cultural heritage institutions and organizations should also consider their capability to enhance all the potential dimensions of the heritage experience. Recent research in this context has demonstrated that latest technologies can play an important role in enhancing the four dimensions of tourists' experience (entertainment, education, esthetics and escape) as identified by Pine and Gilmore (1998). However, with few exceptions (e.g. Jung and tom Dieck, 2017), studies and technologies in this area appear to be limited in their scope and focus to single stages of the visitors' experiential process and dimensions of their cultural heritage experience. This is confirmed by the analysis of a sample of best practice of smart technologies for cultural heritage sites presented in the paper. Moreover, the analysis contributes to the understanding of the potential of these technologies by considering their application in relation to different types of technologies, stages and dimensions of the experience. Starting from the results of the analysis, a framework is presented to leverage the potential of multiple smart technologies throughout the cultural visitors' journey time and space with the purpose of intensifying the different potential dimensions of the visitors' experience at cultural heritage sites. The pilot testing of the model at a real heritage site provides insights into the opportunities to use a combination of technologies for facilitating and enriching visitors' experience according to this integrated view of the heritage experience based on multiple stages and multiple dimensions. Such an integrated perspective of ICTs use in the context of cultural heritage can provide a base for advancing theory and practice. Research on the use of smart technologies at destinations could benefit from more comprehensive analysis of their impact on visitors experience deriving from an integrated multi-stage and multi-dimensional approach. From a theoretical point of view, the proposed framework responds to the call by Kuflik et al. (2015) for new approaches to better 
link pre, during and post visit phases of cultural heritage experiences. Moreover, the framework advances current literature by integrating the potentials of different technologies in relation to this extended, three-stage view of the experience. Most studies on tourism experiences at cultural heritage sites, including the framework proposed by Kuflik et al. (2015) consider the same common technology for each phase of visitors' journey. From a managerial perspective, cultural heritage institutions and destination organizations could find support in such a view when realizing the potential of new technologies in enhancing a rich and memorable experience through specialized smart devices. Such a perspective can also support strategies and investments aimed at the smart development of destinations. Especially in case of destinations endowed with rich cultural resources, the use advanced technologies according to an integrated perspective can become a lever to differentiate a destination from its competitors by providing tourists unique cultural experiences. Future research will be directed to overcome the limits of the present study. These are firstly related to the methodology used, which only considers secondary data. Secondly, the application of the framework to a single case poses significant limits with regards its potential of generalizability. Moreover, the impact of different technologies considered in the framework on the multiple dimensions of the experience needs to be supported by an empirical analysis. This requires an extended investigation to examine visitors' experience and its linkages with smart technologies in the various stages of their visit. Further research will be also directed to identify the opportunities and constraints related to the replicability and industrialization of the proposed framework, by considering its application to other cultural heritage sites.

\section{Acknowledgements}

The project described in this study was funded by the Region of Campania (POR FESR 20072013 OB. 2.1- Creative \& Cultural Lab ProjectsDIP. 54 - DG 91 n. 235/2015). The authors gratefully acknowledge that pilot testing was supported by the Department for Tourism and Cultural Heritage of the Municipality of Naples and by the urban mobility operator ANM.

\section{References}

Addis, M. (2005). New technologies and cultural consumption. Edutainment is born! European Journal of Marketing, 39(7/8), 729-736.

Aho, S.K. (2001). Towards a General Theory of Touristic Experiences: Modelling Experience Process in Tourism. Tourism Review, 56(34), 33-37.

Alexander, J., Barton, J., Goeser, C. (2013). Transforming the Art Museum Experience: Gallery One. Paper presented at the Annual Conference of Museums and the Web, April 17-20, 2013, Portland, OR, USA.

Angelopoulou, A., Economou, D., Bouki, V., Psarrou, A., Jin, L., Pritchard, C., Kolyda, F. (2012). Mobile augmented reality for cultural heritage. In: International Conference on Mobile Wireless Midd-leware, Operating Systems, and Appli-cations. Springer: Berlin Heidelberg, 15-22.

Atzori, L., lera, A., Morabito, G. (2010). The Internet of Things: a survey. Computer Networks, 54(15), 2787-2805.

Bakshi, H., Throsby, D. (2012). New technologies in cultural institutions: theory, evidence and policy implications. International journal of cultural policy, 18(2), 205-222.

Bakshi, H.,Throsby D. (2010). Culture of Innovation: An economic analysis of innovation in arts and cultural organisations. London: NESTA.

Boes, K., Buhalis, D., Inversini, A. (2015). Conceptualising smart tourism destination dimensions. In Information and communication technologies in tourism 2015. Heidelberg: Springer International Publishing, 391-403.

Buhalis, D., Amaranggana, A. (2014). Smart Tourism Destinations. In: Xiang, Z., Tussyadiah, I. (Eds.). Information and Communication Technologies in Tourism 2014. Heidelberg: Springer, 553-564.

Buhalis, D., Wagner, R. (2013). E-destinations: Global best practice in tourism technologies and applications. In: Cantoni L., Xiang Z. (Eds). Information and Communication Technologies in Tourism 2013. Heidelberg: Springer, 119-130.

Buonincontri, P., Marasco, A., Ramkissoon, H. (2017). Visitors' Experience, Place Attachment and Sustainable Behaviour at 
Cultural Heritage Sites: A Conceptual Framework. Sustainability, 9(7), 1112

Buonincontri, P., Micera, R. (2016). The experience co-creation in smart tourism destinations: a multiple case analysis of European destinations. Information Technology \& Tourism, 16(3), 285-315.

Calver, S. J., Page, S. J. (2013). Enlightened hedonism: Exploring the relationship of service value, visitor knowledge and interest, to visitor enjoyment at heritage attractions. Tourism Management, 39, 23-36.

Camarero, C., Garrido, M. J., Vicente, E. (2015). Achieving effective visitor orientation in European museums. Innovation versus custodial. Journal of Cultural Heritage, 16(2), 228-235.

Chen, C.-F., Chen, P.-C. (2013). Another look at the heritage tourism experience. Annals of Tourism Research, 41, 215-243.

Chen, C.F., Chen, F.S. (2010). Experience quality, perceived value, satisfaction and behavioral intentions for heritage tourists. Tourism Management, 31, 29-35.

Chung, N., Han, H., Joun, Y. (2015). Tourists' intention to visit a destination: The role of augmented reality (AR) application for a heritage site. Computers in Human Behavior, 50, 588-599.

Cranmer, E., tom Dieck, M.C., Jung. T. (2017). How can Tourist Attractions profit from Augmented Reality? In. T. Jung \& M. C. tom Dieck (Eds.), Augmented Reality and Virtual Reality - Empowering Human, Place and Business, Springer, Forthcoming

Dickinson, J. E., Ghali, K., Cherrett, T., Speed, C., Davies, N., Norgate S. (2014). Tourism and the smartphone app: capabilities, emerging practice and scope in the travel domain. Current Issues in Tourism, 17(1), 84-101.

Falk, J. H., Dierking, L. D. (2000). Learning from museums: Visitor experiences and the making of meaning. Altamira Press.

Graham, M., Zook, M. (2013). Augmented realities and uneven geographies: explo-ring the geolinguistic contours of the web. Environment and Planning, 45, 77-99.

Gretzel, U., Fesenmaier, D. R., O'Leary, J. T. (2006). The transformation of consumer behaviour. In D. Buhalis and C. Costa (Eds.). Tourism business frontiers.
Burlington, MA: Elsevier/ButterworthHeinemann, 9-18.

Gretzel, U., Sigala, M., Xiang Z., Koo C. (2015) Smart tourism: foundations and developments. Electronic Markets, 25, 179-188.

Guttentag, D.A. (2010) Virtual reality: applications and implications for tourism. Tourism Management 31(5), 637-651.

Hallencreutz, J., Turner, D. M. (2011) Exploring organizational change best practice: Are there any clear-cutmodels and definitions? International Journal of Quality and Service Sciences, 3(1), 60-68.

Han, D. I., Jung, T.,Gibson, A. (2013). Dublin AR: Implementing Augmented Reality (AR) in Tourism, In Z. Xiang and I. Tussyadiah (Eds), Information and Communication Technologies in Tourism (pp. 511-523). Springer Computer Science: New York.

Han, D., Leue, C., Jung, T. (2014). A tourist experience model for augmented reality applications in the urban heritage context. Paper presented at the $12^{\text {th }}$ APacCHRIE Conference, Kuala Lumpur.

Han, D. I., tom Dieck, M. C., Jung, T. (2017). User experience model for augmented reality applications in urban heritage tourism. Journal of Heritage Tourism, 1-16.

Hayes, D., MacLeod, N. (2007). Packaging places: Designing heritage trails using an experience economy perspective to maximize visitor engagement. Journal of vacation Marketing, 13(1), 45-58.

Huang, Y. C., Backman, S. J., Backman, K. F., Moore, D. (2013) Exploring user acceptance of 3D virtual worlds in travel and tourism marketing. Tourism Management, 36, 490-501.

ICOM (International Council of Museums) (2007). Museum Definition. Proceedings of the 21st General Conference in Vienna, Austria. URL: http://icom.museum /thevision/museumdefinition.

Jung, T., tom Dieck, M. C., Lee, H., Chung, N. (2016). Effects of Virtual Reality and Augmented Reality on Visitor Experiences in Museum. In A. Inversini, R. Schegg (Eds). Information and Communication Technologies in Tourism 2016. Springer International Publishing, 621-635.

Jung, T., tom Dieck, M. C., Moorhouse, N., tom Dieck, D. (2017). Tourists' experience of Virtual Reality applications. In 2017 IEEE 
International Conference on Consumer Electronics (ICCE) (pp. 208-210).

Jung, T. H., tom Dieck, M. C. (2017).

Augmented reality, virtual reality and $3 D$ printing for the co-creation of value for the visitor experience at cultural heritage places. Journal of Place Management and Development, 10(2), 140-151.

Jurowski, C. (2009). An Examination of the Four Realms of Tourism Experience Theory. Paper presented at the International CHRIE Conference-Refereed Track. University of Massachusetts - Amherst, July, 29.

Kennedy-Eden, H., Gretzel, U. (2012) A taxonomy of mobile applications in tourism. Ereview of Tourism Research, 10(2), 47-50.

Koo, C., Gretzel, U., Hunter, W. C., Chung, N. (2015), The role of IT in tourism. Asia Pacific Journal of Information Systems, 25(1), 99-104.

Kourouthanassis, P., Boletsis, C., Bardaki, C., Chasanidou, D. (2015). Tourists responses to mobile augmented reality travel guides: The role of emotions on adoption behavior. Pervasive and Mobile Computing, 18, 71-87.

Kuflik, T., Wecker, A. J., Lanir, J., Stock, O. (2015). An integrative framework for extending the boundaries of the museum visit experience: linking the pre, during and post visit phases. Information Technology \& Tourism, 15(1), 17-47.

Lamsfus, C., Grün, C., Alzua-Sorzabal, A., Werthner, H. (2010) Context-based matchmaking to enhance tourists' experiences. Novatica 11, 17-23.

Lamsfus, C., Martín, D., Alzua-Sorzabal, A., Torres-Manzanera, E. (2015). Smart tourism destinations: An extended conception of smart cities focusing on human mobility. In Information and Communication Technologies in Tourism 2015. Heidelberg: Springer International Publishing, 363-375.

Landorf, C. (2009). Managing for sustainable tourism: a review of six cultural World Heritage Sites. Journal of Sustainable Tourism, 17(1), 53-70.

Lee, H., Chung, N. Koo, C. (2015). Moderating Effects of Distrust and Social Influence on Aesthetic Experience of Augmented Reality: Motivation-Opportunity-Ability Model Perspective. In Proceedings of the 17th International Conference on Electronic Commerce 2015, 22.
Lee, K., Lee, H. R., Ham, S. (2013). The Effects of Presence Induced by Smartphone Applications on Tourism: Application to Cultural Heritage Attractions. In Z. Xiang and I. Tussyadiah (eds.) Information and Communication Technologies in Tourism 2014. Heidelberg: Springer, 59-72.

Leue, M. C., Jung, T., tom Dieck, D. (2015). Google Glass augmented reality: Generic learning outcomes for art galleries. In Information and Communication Technologies in Tourism 2015. Heidelberg: Springer, 463-476.

Mannell, R.E., Iso-Ahola, S.E. (1987). Psychological Nature of Leisure and Tourism Experience. Annals of Tourism Research, 14(3), 314-331.

Marty P.F. (2007). Museum websites and museum visitors: before and after the museum visit. Museum Manage Curatorship, 22(4), 337-360.

Masberg, B., Silverman, L. (1996). Visitor experiences at heritage sites: a phenomenological approach. Journal of Travel Research, 34(4), 20-25.

Mclntosh, A.J. (1999). Into the Tourist's Mind: Understanding the Value of the Heritage Experience. Journal of Travel \& Tourism Marketing, 8(1), 41-64.

McIntosh, A.J., Prentice, R.C. (1999). Affirming authenticity: Consuming cultural heritage. Annals of Tourism Research, 26(3), 589-612.

Mehmetoglu, M., Engen, M. (2011). Pine and Gilmore's Concept of Experience Economy and Its Dimensions: An Empirical Examination in Tourism. Journal of Quality Assurance in Hospitality \& Tourism, 12(4), 237-255.

Mortara, M., Catalano, C. E., Bellotti, F., Fiucci, G., Houry-Panchetti, M., Petridis, P. (2014). Learning cultural heritage by serious games. Journal of Cultural Heritage, 15(3), 318-325.

Neuhofer, B., Buhalis, D., Ladkin, A. (2015). Smart technologies for personalized experiences: a case study in the hospitality domain. Electronic Markets - The International Journal of Networked Business, 25(3), 243-254.

Neuhofer, B., Buhalis, D., Ladkin, A. (2012). Conceptualising technology enhanced destination experiences. Journal of Destination Marketing \& Management, 1(1), 36-46. 
Oh, H., Fiore, A.M., Jeoung, M. (2007). Measuring experience economy concepts: Tourism Applications. Journal of Travel Research, 46, 119-132.

Pantano, E. (2011). Virtual cultural heritage consumption: a 3D learning experience. International Journal of Technology Enhanced Learning, 3(5), 482-495.

Pine, B. J., Gilmore, J.H. (1998). Welcome to the experience economy. Harvard Business Review, 76 (July-August), 97-105.

Quadri-Felitti, D., Fiore, A.M. (2012). Experience economy constructs as a framework for understanding wine tourism. Journal of Vacation Marketing, 18(1), 3-15.

Radder, L., Han, X. (2015). An examination of the museum experience based on Pine and Gilmore's experience economy realms. The Journal of Applied Business Research, 31(2), 455-470.

Sheng, C. W., Chen, M. C. (2012). A study of experience expectations of museum visitors. Tourism Management, 33(1), 53-60.

Stamboulis, Y., Skayannis, P. (2003). Innovation Strategies and Technology for Experience-Based Tourism. Tourism Management, 24, 35-43.

Suntikul, W., Jachna, T. (2016). Profiling the heritage experience in Macao's Historic Center. International Journal of Tourism Research, 18, 308-318.

tom Dieck, M. C., Jung, T. (2015). A theoretical model of mobile augmented reality acceptance in urban heritage tourism. Current Issues in Tourism, 1-21.

tom Dieck, M. C., Jung, T. H., \& tom Dieck, D. (2016). Enhancing art gallery visitors' learning experience using wearable augmented reality: generic learning outcomes perspective. Current Issues in Tourism, 1-21.

tom Dieck, M. C., \& Jung, T. H. (2017). Value of augmented reality at cultural heritage sites: A stakeholder approach. Journal of Destination Marketing \& Management, 6 (2), 110-117. tom Dieck, M. C., Jung, T., Han, D. (2016), Mapping requirements for the wearable smart glasses augmented reality museum application. Journal of Hospitality and Tourism Technology, 7 (3), 230-253.

Tscheu, F. Buhalis, D. (2016). Augmented Reality at Cultural Heritage sites. In A. Inversini, R. Schegg (Eds). Information and Communication Technologies in Tourism 2016. Springer International Publishing, 607-619.

Tussyadiah I. (2013). Expectation of Travel Experiences with Wearable Computing Devices. In: Xiang Z., Tussyadiah I. (eds) Information and Communication Technologies in Tourism 2014. Springer, Cham.

Tussyadiah, I. (2015). Personal Technology and Tourism Experiences. In: Egger, R., and Maurer, C. (Eds.). Tourism Research Perspectives. Proceedings of the International Student conference in Tourism Research. Norderstedt: BoD, 1-10.

Tussyadiah, I. P., Wang, D., \& Jia, C. H. (2017). Virtual Reality and Attitudes Toward Tourism Destinations. In Information and Communication Technologies in Tourism 2017 (pp. 229-239). Springer, Cham.

Tussyadiah, I. P., Jung, T. H., \& tom Dieck, M. C. (2017). Embodiment of Wearable Augmented Reality Technology in Tourism Experiences. Journal of Travel Research, DOI: https://doi.org/10.1177/0047287517709090

Vlahakis,V., Ioannidis, N. Karigiannis, J. Tsotros, M. Gounaris, M. Stricker, D. Gleue, T., Daehne, P., Almeida, L. (2002). Archeoguide: an augmented reality guide for archaeological sites, IEEE Computer Graphics \& Applications 22(5), 52-60.

Wang, D., Xiang, Z. (2012). The new landscape of travel: A comprehensive analysis of smartphone apps. In M. Fuchs et al. (eds.). Information and communication technologies in tourism. Springer-Verlag, 308-319.

Want, R., Schilit, B. N., Jenson, S. (2015) Enabling the Internet of Things. Computer, 1, 28-35. 